\title{
AUTOGESTÃO DA SAÚDE E DO CORPO: A INFLUÊNCIA DO PARADIGMA BIOMÉDICO
}

\author{
DRA. SÍLVIA MARIA AGATTI LÜDORF \\ Professora Adjunta da Escola de Educação Física e Desportos (EEFD) da \\ Universidade Federal do Rio de Janeiro (UFRJ); Doutora em Educação pela \\ Universidade Federal do Rio de Janeiro. Coordenadora do Núcleo de \\ Estudos Sociocorporais e Pedagógicos em Educação Física e Esportes (NESPEFE/EEFD/UFRJ) \\ (Rio de Janeiro - Rio de Janeiro - Brasil) \\ E-mail: sagatti@ufrj.br
}

\author{
MS. ALAN CAMARGO SILVA \\ Mestre em Educação Física pela Escola de Educação Física e Desportos \\ da Universidade Federal do Rio de Janeiro (EEFD/UFRJ) \\ Membro do Núcleo de Estudos Sociocorporais e Pedagógicos em Educação \\ Física e Esportes (NESPEFE/EEFD/UFRJ) (Rio de Janeiro - Rio de Janeiro - Brasil) \\ E-mail: alan10@zipmail.com.br
}

\begin{abstract}
RESUMO
A presente resenha se refere à obra "Corpo em evidência: a ciência e a redefinição do humano", de autoria de Francisco Ortega e de Rafaela Zorzanelli. Por meio de uma linguagem acessível e instigante, calcados em uma reflexão crítica e atual, os autores abordam como o corpo vem sendo cada vez mais compreendido pela sociedade contemporânea à luz das explicações científicas provindas do referencial biomédico e tecnológico. As formas de se olhar e cientificizar o corpo, a autogestão da saúde e o determinismo biológico, em contexto marcado pela somatização e pela exteriorização, são as principais temáticas abordadas. Esse cenário teórico, desenvolvido com rigor e profundidade pelos autores, leva a questionar e refletir como tais aspectos atravessam a área da Educação Física.
\end{abstract}

PALAVRAS-CHAVE: Corpo; ciência; saúde; educação física. 
ORTEGA, F.; ZORZANELLI, R. Corpo em evidência: a ciência e a redefinição do humano. Rio de Janeiro: Civilização Brasileira, 2010. $192 \mathrm{p}$.

Francisco Ortega é filósofo e autor de vários livros e artigos, muitos deles voltados ao estudo da corporeidade. Ao tratar de temáticas como subjetividade, saúde, corpo e ciência no contexto contemporâneo, tem se tornado um referencial a ser considerado nos estudos envolvendo estes assuntos. Na obra "Corpo em evidência: a ciência e a redefinição do humano", acompanhado de Rafaela Zorzanelli, os autores argumentam que o corpo adquiriu notoriedade na sociedade contemporânea, principalmente em decorrência da influência do paradigma biomédico e de sua tradição de objetividade, rigor e cientificidade.

Tal paradigma fundamenta em grande medida as raízes da área de Educação Física (SOARES, 2004). Para Bracht ( I999, p. 73), o nascimento da Educação Física "[...] foi também legitimado pelo conhecimento médico-científico do corpo que referendava as possibilidades, a necessidade e as vantagens de tal intervenção sobre o corpo." Para compreender melhor o papel das ciências biomédicas nos estudos sobre corpo e saúde, bem como os limites e possibilidades dessa relação e as implicações para a própria Educação Física, é que se faz imperiosa a leitura desse livro.

No primeiro capítulo, "O corpo e sua visualização na medicina", são abordados aspectos significativos do desenvolvimento dos instrumentos de visualização corporal. Os autores apóiam-se na premissa de que a visualidade apresenta relação direta com a "produção de verdades científicas sobre o corpo" (ORTEGA; ZORZANELLI, 2010 , p. 17). Sabe-se que, historicamente, o acesso ao interior do corpo na busca de compreensão das doenças, o reduziu ao seu caráter objetivo, mensurável e fragmentado, destituindo-o do sujeito (ORTEGA, 2008; LE BRETON, 20 I I).

Dos raios $X$ às novas técnicas de imageamento corporais, a medicina, a partir do privilégio da visão, vem se servindo dessas tecnologias para decifrar o funcionamento do corpo e a relação com o processo saúde-doença. Contudo, para Ortega e Zorzanelli, diagnosticar doenças através das visualizações médicas, ainda que com o respaldo da objetividade e neutralidade, pode ser uma ilusão, uma vez que a decodificação da imagem exige capacidade interpretativa, além das causas das doenças serem complexas e multifatoriais.

O segundo capítulo, "A saúde como salvação: contexto cultural de ascensão do corpo como valor na contemporaneidade", traz uma reflexão sobre os modos 
de subjetivação contemporâneos que, conforme os autores, passam por processos de somatização e exteriorização. Aspectos-chave da subjetividade são definidos em termos corporais e biomédicos, amparados pela exposição do corpo, da vida privada e pelas tecnologias comunicacionais.

Os autores retomam, breve e criticamente, as formas de poder delineadas por Foucault, e argumentam que a biopolítica na atualidade apresenta nuances como a autogestão da saúde e a capitalização da vida, inovando nas formas de vigiar o corpo com foco na saúde. Para Ortega e Zorzanelli, nesse novo contexto, observa-se a criação de biovalores, ou seja, matérias orgânicas valiosas, como genes, células-tronco, etc, e de diferentes formas de cidadania, como a biossociabilidade. A biossociabilidade seria o agrupamento de pessoas mediante critérios de desempenho físico, doenças e saúde, dentre outros. Tal processo de transformação das identidades provoca mudanças também nos conceitos de natural/artificial e normal/ patológico em relação ao corpo, uma vez que não há mais distinções claras ou ideias totalizantes a esse respeito.

No terceiro capítulo, "Vírus, genes, cérebro e outros reducionismos na contemporaneidade", Ortega e Zorzanelli centram suas análises em torno do determinismo das explicações sobre o processo saúde-doença exclusivamente a partir do aspecto biológico, como alguns autores também denunciam (HELMAN, 2003; HERZLICH, 2004). Entretanto, o livro baseia-se particularmente nas reflexões relacionadas ao cérebro pela notória evidência como determinante para uma série de doenças, como pode ser visto amplamente no incessante desenvolvimento do campo das neurociências nos últimos anos. A relação histórica entre associar a mente, traduzida pelo conjunto de aspectos morais e intelectuais que singularizam o sujeito, ao cérebro, órgão que oferece suporte na recepção de informações do ambiente, a fim de produzir respostas adequadas, cria a imagem do "sujeito cerebral".

Nesse contexto sociocultural, que possibilita a relação entre a anatomia craniana e a sua configuração dirigida ao funcionamento cerebral, emerge o processo que Ortega e Zorzanelli denominam de "cerebralização da identidade". Cada vez mais, na sociedade contemporânea, encarnada da cultura somática, o cérebro ofereceria explicações científicas lógicas que determinariam os comportamentos e classificariam a identidade normal ou patológica do sujeito, desconsiderando que o indivíduo, como Latour (2004) destaca, é um ser híbrido entre o natural e o social. Nessa direção, Ortega e Zorzanelli discutem sobre as interfaces reducionistas entre as neurociências e as ciências humanas, elegendo o caso da neuroeducação e da neuropsicanálise. 
No último capítulo, intitulado "O corpo apesar das tecnologias: novas formas de sofrimento e o dilema psicossomático", os autores argumentam que o sofrimento do corpo causado pelas patologias consideradas da contemporaneidade são essencialmente as mesmas do século XIX. No entanto, atualmente, influenciado pelo discurso médico-científico, o indivíduo é cada vez mais responsável pela eficácia em administrar cuidados de si visando à saúde (agência), como se fosse imune a inúmeros determinantes socioculturais.

Destarte, quando a ciência médica, por falta de evidências baseadas em marcadores biológicos, não consegue compreender determinadas patologias - consideradas psicossomáticas, ou na preferência dos autores, doenças sem explicação médica -, há uma estigmatização do sujeito, por ser considerado culpado pela inabilidade de empowerment diante do processo saúde-doença, deslegitimando aquilo que não pode ser atestável/ mensurável por exames: a subjetividade.

As argumentações apresentadas pelos autores, relativas ao contexto da medicina, desde seus primórdios até a contemporaneidade, podem ser praticamente transpostas, além de serem bastante elucidativas, para o cenário da Educação Física. As formas de se olhar e cientificizar o corpo, a autogestão da saúde e o determinismo biológico, em contexto marcado pela somatização e pela exteriorização, são alguns dos aspectos centrais que mereceriam mais debates na área.

Compreender em que medida o enraizamento médico e biológico sedimentou o desenvolvimento e continua a ser uma das principais referências para muitas das práticas da Educação Física, ajuda a compreender, inclusive, como (e por que) a área se delineia da forma atual. Manoel e Carvalho (20 I I), em estudo que pode ser considerado emblemático das discussões atuais em Educação Física, ao analisarem o contexto da pós-graduação, detectaram o favorecimento de subáreas fundamentadas nas ciências biológicas, em detrimento daquelas orientadas para investigações de natureza educacional e sociocultural.

Espera-se que, neste exercício de problematização incitado pelo texto, se possa refletir sobre as concepções e os significados atribuídos ao corpo, saúde e ciência vigentes na área de Educação Física. Principalmente no âmbito de pesquisa, é fundamental compreender tais noções e estranhá-las no sentido proposto por DaMatta (20 I 0), isto é, de buscar relativizar e indagar as representações que, muitas vezes, se estabelecem como realidades aparentemente dadas e imutáveis.

Ortega e Zorzanelli oferecem um texto sintético, porém de vigor teórico ímpar, proporcionando reflexões indispensáveis para os estudos que permeiam o campo de intervenção da Educação Física, seja com base nos referenciais teóricos da área biomédica ou das Ciências Humanas e Sociais. 


\section{Self-management of the health and the body: the biomedical paradigm's influence}

ABSTRACT: This book review is related to "Body in evidence: science and the redefinition of human" written by Francisco Ortega and Rafaela Zorzanelli. Using an accessible and instigating language, based in an actual and critical reflection, the authors focus on how the body has been increasingly conceived by the scientific explanations derived from the biomedical and technological references, in the contemporary society. The way we see and make the body scientific, the self-management of health and the biological determinism, inside a context that privileges the outer and the body, are the main themes treated in this work. This theoretical scenario, rigorously developed by the authors, guides us to question and reflect about these aspects in the area of Physical Education.

KEYWORDS: Body; science; health; physical education.

\section{Autogestión de la salud y del cuerpo: la influencia del paradigma biomédico}

RESUMEN: La presente reseña se refiere a la obra "Cuerpo en evidencia: la ciencia y la redefinición del humano" de autoría de Francisco Ortega e de Rafaela Zorzanelli. Con un lenguaje accesible e instigador, los autores presentan una reflexión crítica y actual de cómo la sociedad contemporánea viene comprendiendo el cuerpo a partir de suyas explicaciones científicas emanadas del referencial biomédico y tecnológico. Las formas de mirar y tornar el cuerpo científico, la autogestión de la salud y el determinismo biológico, en un contexto marcado por la somatización y exteriorización, son las principales temáticas abordadas. Ese escenario teórico, desarrollado con rigor y profundidad por los autores, leva a cuestionar y reflejar cómo estos aspectos atraviesan la zona de la Educación Física.

PALABRAS CLAVE: Cuerpo; ciencia; salud; educación física.

\section{REFERÊNCIAS}

BRACHT, V. A constituição das teorias pedagógicas da Educação Física. Cadernos Cedes, Campinas, v. 19, n. 48, p. 69-88, ago. 1999.

DAMATTA, R. Relativizando: uma introdução à antropologia social. Rio de Janeiro: Rocco, 2010.

HELMAN, C. G. Cultura, saúde e doença. 4. ed. Porto Alegre: Artes Médicas, 2003.

HERZLICH, C. Saúde e doença no início do século XXI: entre a experiência privada e a esfera pública. Physis: Revista de Saúde Coletiva, Rio de Janeiro, v. I4, n. 2, p. 383-394, 2004.

MANOEL, E. J.; CARVALHO, Y. M. Pós-graduação na educação física brasileira: a atração (fatal) para a biodinâmica. Educação e Pesquisa, São Paulo, v. 37, n. 2, p. 389-406, maio/ago. 201 I .

LATOUR, B. How to talk about the body? the normative dimension of science studies. Body \& Society, London, v. 10, n. 2/3, p. 205-229, 2004. 
LE BRETON, D. Antropologia do corpo e modernidade. Petrópolis: Vozes, 2011 .

ORTEGA, F. O corpo incerto: corporeidade, tecnologias médicas e cultura contemporânea. Rio de Janeiro: Garamond, 2008.

SOARES, C. L. Educação Física: raízes européias e Brasil. 3. ed. Campinas: Autores Associados, 2004.

Recebido: 23 dez. 201 I

Aprovado: 30 mar. 2012

Endereço para correspondência:

Alan Camargo Silva

Av. Marechal Henrique Lott, n. 70 / apt. 1014

Barra da Tijuca

Rio de Janeiro-RJ

CEP: 2263 I-370 